Original Article

Artigo Original

Priscila Weber ${ }^{1}$

Eliane Castilhos Rodrigues Corrêa ${ }^{2}$

Fabiana dos Santos Ferreira ${ }^{1}$

Juliana Corrêa Soares ${ }^{1}$

Geovana de Paula Bolzan ${ }^{3}$

Ana Maria Toniolo da Silva ${ }^{2}$

Keywords

Facial pain

Neck pain

Craniomandibular disorders

Posture

Cephalometry

Signs and symptoms

Descritores

Dor facial

Cervicalgia

Transtornos craniomandibulares

Postura

Circunferência craniana

Sinais e sintomas

Correspondence address:

Priscila Weber

Av. Presidente Vargas, 1855/1101, Centro, Santa Maria (RS), Brasil, CEP: 97015-513.

E-mail: prifisio07@yahoo.com.br

Received: 5/27/2011

Accepted: 10/6/2011

\section{Cervical spine dysfunction signs and symptoms in individuals with temporomandibular disorder}

\author{
Frequência de sinais e sintomas de disfunção cervical em \\ indivíduos com disfunção temporomandibular
}

\begin{abstract}
Purpose: To study the frequency of cervical spine dysfunction (CCD) signs and symptoms in subjects with and without temporomandibular disorder (TMD) and to assess the craniocervical posture influence on TMD and CCD coexistence. Methods: Participants were 71 women (19 to 35 years), assessed about TMD presence; 34 constituted the TMD group (G1) and 37 comprised the group without TMD (G2). The CCD was evaluated through the Craniocervical Dysfunction Index and the Cervical Mobility Index. Subjects were also questioned about cervical pain. Craniocervical posture was assessed by cephalometric analysis. Results: There was no difference in the craniocervical posture between groups. G2 presented more mild CCD frequency and less moderate and severe CCD frequency $(\mathrm{p}=0.01)$. G1 presented higher percentage of pain during movements $(\mathrm{p}=0.03$ ) and pain during cervical muscles palpation ( $\mathrm{p}=0.01$ ) compared to $\mathrm{G} 2$. Most of the TMD patients $(88.24 \%)$ related cervical pain with significant difference when compared to $\mathrm{G} 2(\mathrm{p}=0.00)$. Conclusion: Craniocervical posture assessment showed no difference between groups, suggesting that postural alterations could be more related to the CCD. Presence of TMD resulted in higher frequency of cervical pain symptom. Thus the coexistence of CCD and TMD signs and symptoms appear to be more related to the common innervations of the trigeminocervical complex and hyperalgesia of the TMD patients than to craniocervical posture deviations.
\end{abstract}

\section{RESUMO}

Objetivos: Investigar a frequência de sinais e sintomas de disfunção da coluna cervical (DCC) em indivíduos com e sem disfunção temporomandibular (DTM) e avaliar a influência da postura craniocervical sobre a coexistência da DTM e da DCC. Métodos: Participaram 71 mulheres, com idades entre 19 e 35 anos, que foram avaliadas quanto à presença de DTM. Destas, 34 constituíram o grupo com DTM (G1) e 37 participaram compuseram o grupo sem DTM (G2). A DCC foi avaliada pelo Índice de Disfunção Clínica Craniocervical e pelo Índice de Mobilidade Cervical. Questionou-se, ainda, a queixa de dor cervical. A postura craniocervical foi aferida por meio do traçado cefalométrico. Resultados: Não houve diferença na entre os grupos quanto à postura craniocervical. O G2 apresentou maior frequência de DCC leve e menor frequência de DCC moderada ou grave $(0,01)$. O G1 apresentou maiores percentuais de frequência de dor durante a execução do movimento e dor à palpação dos músculos cervicais. No G1, a maioria $(88,24 \%)$ das participantes relatou dor cervical, com diferença em relação ao G2. Conclusão: Não houve diferença na postura craniocervical entre os grupos, o que sugere que as alterações posturais estejam mais relacionadas à ocorrência de DCC. A presença de DTM resultou em maior frequência de sintomas dolorosos na região cervical. Assim, a coexistência de sinais e sintomas de DCC e DTM parece estar mais relacionada à inervação comum do complexo trigêmino-cervical e à hiperalgesia de indivíduos com DTM do que à alteração postural craniocervical.

Study conducted at the Graduate Program in Human Communication Disorders, Department of Speech-Language Pathology and Audiology, Universidade Federal de Santa Maria - UFSM - Santa Maria (RS), Brazil.

(1) Graduate Program (Masters degree) in Human Communication Disorders, Department of Speech-Language Pathology and Audiology, Universidade Federal de Santa Maria - UFSM - Santa Maria (RS), Brazil.

(2) Graduate Program in Human Communication Disorders, Department of Speech-Language Pathology and Audiology, Universidade Federal de Santa Maria - UFSM - Santa Maria (RS), Brazil.

(3) Graduate Program (Doctorate degree) in Human Communication Disorders, Department of Speech-Language Pathology and Audiology, Universidade Federal de Santa Maria - UFSM - Santa Maria (RS), Brazil.

Grants: Coordenação de Aperfeiçoamento de Pessoal de Nível Superior (CAPES)

Conflict of interests: None 


\section{INTRODUCTION}

The cervical spine dysfunction (CCD) is a common condition. It is represented by a group of signs and symptoms that involve pain and limitation of range of the physiological movements, tenderness and/or pain on cervical muscles at palpation, besides the presence of articular noises and important craniocervical posture changes ${ }^{(1-4)}$. Due to the close anatomical and functional relation that involves the craniocervicomandibular system, several studies have reported a high prevalence of signs and symptoms of CCD in subjects with temporomandibular disorder (TMD) ${ }^{(1,5-10)}$.

Hypothesis based on the biomechanical and neurophysiological aspects can be found in the literature aiming to explain the CCD and TMD coexistence. One of them points out to the postural changes of the head and cervical spine as a common causal and/or maintaining factor for such disorders. The forward head posture is frequently related to the neck pain ${ }^{(11)}$ due to the overload of the posterior cervical muscles in the atempt to keep the head balance over the spine. This posture is also related to TMD because of the modification of the mandibular condyle position that, in its turn, overloads the temporomandibular joints ${ }^{(12,13)}$.

The interdependence between the sensoriomotor cervical and trigeminal systems is another possible cause of the TMD and CCD coexistence. Studies have reported the existence of a convergence of the cervical sensorial information with the afferent trigeminal nerves, which supply the orofacial region ${ }^{(14)}$. In addition to the common innervations, other studies concluded that TMD patients present a hyperexcitability of the nociceptive central neurons combined with an unbalance of the descendent inhibitory paths that regulate the pain processing ${ }^{(15,16)}$. Thus, subjects with craniomandibular disorders may report persistent pain in several parts of their body, mainly in the cervical region, due to its proximity to the orofacial region.

Considering the clinical implications that coexist in the relation between the dysfunctions that affect the craniocervicomandibular system, the present study proposed to investigate the frequency of signs and symptoms of CCD in subjects with and without TMD. Additionally, the influence of the craniocervical posture of these subjects on the TMD and DCC coexistence was evaluated. The results of the present study may provide useful support to the diagnosis and treatment of individuals with craniocervicomandibular disorders.

\section{METHODS}

\section{Subjects}

Women, 19 to 35 years of age, interested on a functional assessment of the orofacial and cervical regions were invited to take part in this study. The subjects were clarified about the purposes and procedures of the study and were included after signing the consent form. The project for this research was approved by the Ethics Committee in Research in Health of the Universidade Federal de Santa Maria (UFSM), under protocol number 0048.0.243.000-08.
The exclusion criteria of the study were: neuropsicomotor disease; facial and/or craniocervical trauma, deformities or surgical procedures; diagnostic of cervical herniated disc and current physiotherapeutic treatment and use of braces.

Out of the group of volunteers who contacted the researcher, 71 were selected to participate in the study. They were divided in two groups according to the presence of signs and symptoms of TMD. Subjects with one or more TMD diagnosis according to Research Diagnostic Criteria for Temporomadibular Disorder (RDC/TMD) $)^{(17)}$ were selected to form group 1 (G1). Group 2 (G2) was comprised by subjects that did not present any signs or symptoms of TMD according to RDC/TMD.

Thus, G1 was comprised by 34 women, mean age $23.4 \pm 3.4$ years and Body Mass Index (BMI) of $22 \pm 3.44 \mathrm{~kg} / \mathrm{cm}^{2}$. he G2 consisted of 37 women, mean age 23.8 \pm 3.4 years and BMI of $22.2 \pm 3.62 \mathrm{~kg} / \mathrm{cm}^{2}$.

\section{Temporomandibular disorder evaluation}

All subjects underwent physical evaluation by RDC/TMD protocol, conducted by a single qualified examiner. The RDC/ TMD diagnostic sub-groups are: myofascial disorders (Group I), disk displacements (Group II), arthralgia, osteoarthritis and osteoarthrosis (Group III). Each subject could present, at most, one muscular diagnostic (Group I) added to a one Group II diagnostic and one group III diagnostic for each temporomandibular joint separately.

\section{Cervical dysfunction evaluation}

For cervical spine assessment the Craniocervical Dysfunction Index (CCDI) and the Cervical Mobility Index $(\mathrm{CMI})^{(3)}$, which classifies the individual with respect of absence or presence of mild, moderate and severe dysfunction were used.

The CCDI has five items which measures: the range of cervical movements, pain reported during these movements performance, cervical joint changes (noise, click or blockage of vertebral articulation on movements), pain reported at cervical muscle palpation, and craniocervical posture. For CMI evaluation all physiological cervical ranges of motion were measured using a fleximeter. These tests were carried out by a single trained examiner.

Considering that CCDI assesses only the pain symptoms referred during the provoked pain tests of movement and cervical muscle palpation, it was also questioned, in the anamnesis, the complaint of pain on cervical region. The presence of this complaint characterized CCD as symptomatic and, your absence with CCDI alterations, as silent CCD.

\section{Craniocervical posture evaluation}

For the cephalometric analysis, the volunteers underwent a right lateral cranium and cervical column radiograph in orthostatic position. In order to reproduce the natural head positioning, the volunteers were oriented to glance at their eyes in a mirror placed at one-meter distance ${ }^{(2,18)}$. 
At lateral radiograph register, three variables referent to head and cervical spine posture were evaluated. Flexion/extension head position in relation to superior cervical spine was measured through Rocabado craniovertebral angle, recently referred on literature ${ }^{(19-21)}$. This angle is formed by McGregor Plan (plan which tangencies the base of the occipital bone till it reaches the posterior nasal spine) and the Odontoid Plan (which comes from the top of the odontoid process of $\mathrm{C} 2$ till a most anterior and inferior point of the body of $\mathrm{C} 2$ ).

The forward head posture was evaluated through an angle formed by the intersection of CPL line (Craniocervical Postural Line) in relation to the true horizontal line ${ }^{(18)}$. The CPL line tangencies the central points demarcated on the body of the first six cervical vertebrae.

To the analysis of the cervical spine the CVT/EVT ratio was used $^{(21,22)}$. The CVT line intercepts the apex of the bone prominence of the second cervical vertebra and the most posterior and inferior point of the fourth cervical vertebra. The EVT line intercepts the most posterior and inferior points of the fourth and five cervical vertebrae.

The variables were measured manually by only one examiner. Fifteen radiographs were randomly selected for a second analysis after one week in order to verify the cephalometric trace reliability.

\section{Statistical analysis}

The intra-class correlation coefficient - ICC (software SPSS 17.0 ) verified the reliability of the cephalometric measurements. ICC values above 0.70 are usually used as "sufficiently reproducible" thresholds. Values under 0.70 are consider not acceptable, between 0.91 and 0.79 acceptable, between 0.80 and 0.89 very satisfactory and above 0.90 , excellent. The other analyses were done through the software STATISTICA 7.1. To verify data's normality, the Lilliefors test was used in the cephalometric variables and in age and ICM demographic variables. For comparison among averages the non parametric Mann-Whitney test for independent samples was used. A descriptive statistics verified the subject percentage of volunteers in each group, according to the presence of temporomandibular disorder, cervical dysfunction degree and sub-items of Craniocervical Dysfunction Index - CCDI. The Chi-square test analyzed the difference of the percentage between the groups. A significance level of $5 \%(\mathrm{p}<0.05)$ was admitted.

\section{RESULTS}

Out of 71 assessed subjects, $52.11 \%(\mathrm{n}=37)$ did not present symptoms and/or clinical signs of TMD. Yet, in $47.88 \%(n=34)$ at least one TMD diagnostic was detected: $41.1 \%$ myofascial TMD; $47.05 \%$ mixed TMD, i.e., myofascial pain associated to group II and/or III TMD diagnostic and $11.76 \%$ presented only group III TMD diagnostic. With reference to demographic data, the groups were homogeneous, with no differences related to age $(\mathrm{p}=0.1)$ and $\mathrm{BMI}(\mathrm{p}=0.7)$.

The ICC results referring the postural variables demonstrated excellent reliability levels (CPL/Hor $=0.95$; CVT/
$\mathrm{EVT}=0.99 ; \mathrm{ACV}=0.98)$. The craniocervical posture was similar between the groups (Table 1).

Table 1. Comparison between $\mathrm{G} 1$ and $\mathrm{G} 2$ groups regarding craniocervical posture variables

\begin{tabular}{lccccc}
\hline \multirow{2}{*}{$\begin{array}{l}\text { Postural } \\
\text { variables }\end{array}$} & \multicolumn{2}{c}{$\mathrm{G} 1(\mathrm{n}=34)$} & \multicolumn{2}{c}{$\mathrm{G} 2(\mathrm{n}=37)$} & \\
\cline { 2 - 5 } & Mean & $\mathrm{SD}$ & Mean & $\mathrm{SD}$ & \\
\hline CPL/Hor & 81 & 4.9 & 82 & 5.1 & 0.72 \\
EVT/CVT & 4.4 & 7.2 & 3.5 & 8.7 & 0.16 \\
CVA & 102 & 7.6 & 101 & 8.3 & 0.13 \\
\hline
\end{tabular}

Mann-Whitney test $(p<0.05)$

Note: G1 = temporomandibular disorder group; G2 = group without temporomandibular disorder; $\mathrm{SD}=$ standard deviation; $\mathrm{CPL} / \mathrm{Hor}=$ forward head posture angle; EVT/CVT = cervical lordosis angle; CVA = craniovertebral angle, referent to flexion/extension position of the head

The G2 subjects presented higher frequency of light CCD and lower frequency of moderate and severe CDD than G1 subjects $(\mathrm{p}=0.01)$ (Figure 1$)$.

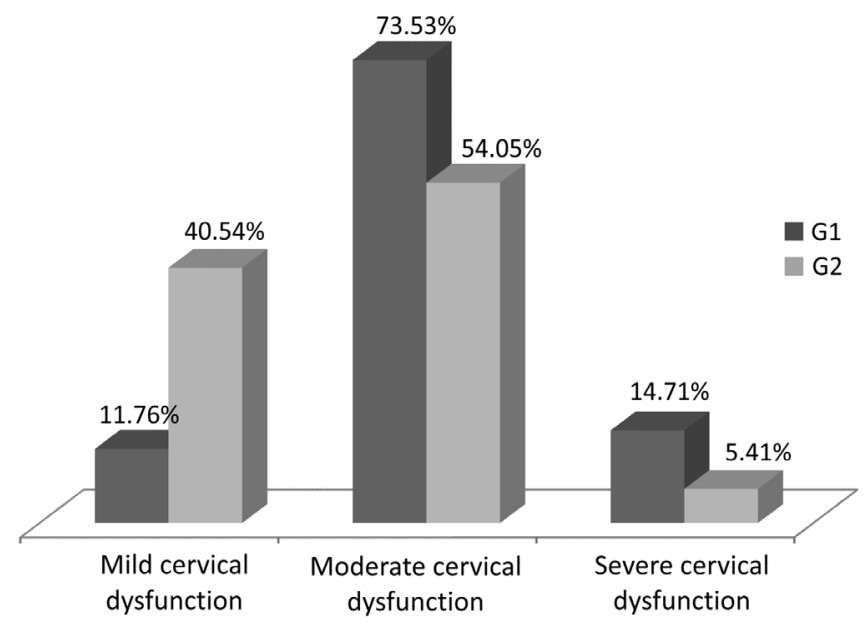

Note: G1 = temporomandibular disorder group; G2 = group without temporomandibular disorder

Figure 1. Subjects with and without temporomandibular disorder classified according to the extension of cervical spine dysfunction

Subjects of G1 presented a higher percentage of pain complaint in the cervical region, compared to the $\mathrm{G} 2(\mathrm{p}=0.00)$ (Figure2).

There were differences between the groups regarding the provoked pain symptom in the cervical region. In pain evaluation during movement, G1 presented higher frequency of pain symptom in at least one movement compared to the $\mathrm{G} 2(\mathrm{p}=0.03)$. During cervical muscles palpation, the results showed reference of pain in a greater number of areas in $\mathrm{G} 1$ $(\mathrm{p}=0.01)($ Table 2$)$

\section{DISCUSSION}

The cephalometric analysis demonstrated that the craniocervical posture was similar in both groups. This result reinforces the data of recent studies ${ }^{(19,20)}$, which did not find postural 
Table 2. Clinical signs of CCD according with TMD diagnostic

\begin{tabular}{|c|c|c|c|c|c|c|}
\hline \multirow{2}{*}{ Clinical signs } & & \multicolumn{2}{|c|}{ G1 $(n=34)$} & \multicolumn{2}{|c|}{ G2 $(n=37)$} & \multirow[t]{2}{*}{$\mathrm{p}$-value } \\
\hline & & $\%$ & $f$ & $\%$ & $f$ & \\
\hline \multirow{2}{*}{ Cervical mobility } & Normal & 15 & 44.12 & 18 & 48.65 & \\
\hline & Severely damaged & 0 & 0 & 0 & 0 & \\
\hline Pain on movement & Pain on movement & 17 & 50 & 28 & 75.68 & \\
\hline \multirow{3}{*}{ Articular function } & Soft movement & 27 & 79.41 & 35 & 94.59 & \\
\hline & Sounds on movement & 7 & 20.59 & 2 & 5.41 & 0.05 \\
\hline & Blockage on movement & 0 & 0 & 0 & 0 & \\
\hline Muscle palpation & Painless palpation & 0 & 0 & 0 & 0 & \\
\hline
\end{tabular}

*Significant values, $(p<0,05)-$ Chi-square test

Note: $\mathrm{G} 1$ = temporomandibular disorder group; $\mathrm{G} 2$ = group without temporomandibular disorder; $f=$ frequency; $C \mathrm{CD}=\mathrm{cervical}$ spine dysphunction; $\mathrm{TMD}=$ temporomandibular disorder

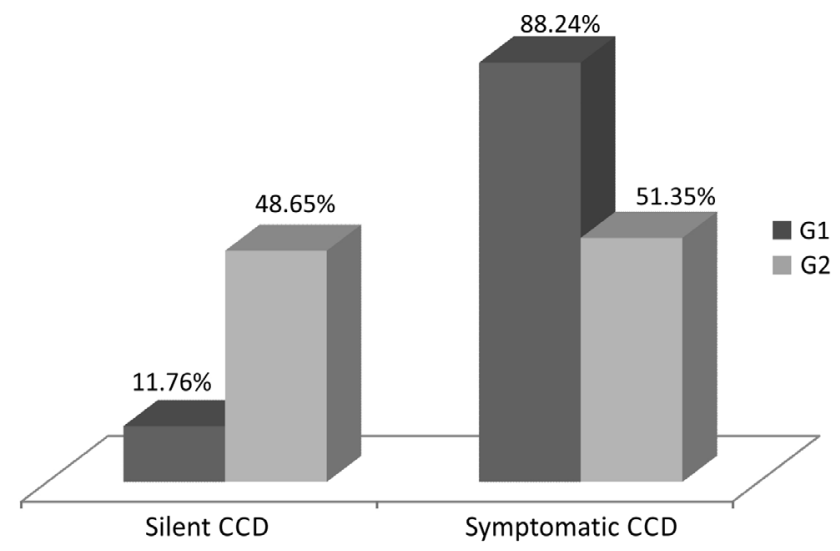

Note: G1 = temporomandibular disorder group; G2 = group without temporomandibular disorder; $C C D=$ craniocervical dysfunction

Figure 2. Percentage results of silent and symptomatic cervical dysfunction occurrence among subjects divided according to the presence of temporomandibular disorder

differences between patients with TMD and asymptomatic individuals. Such studies also used the cephalometric analysis and RDC/TMD to the TMD diagnostic.

Therefore, the hypothesis that the craniocervical postural changes may influence in the highest frequency of the signs and symptoms of CCD in subjects with TMD was rejected. Additionally, considering the direct biomechanical relation of the muscles and cervical spine in the maintenance of head balance, it seems that the postural changes are more related to the occurrence of CCD, as previously demonstrated by other studies ${ }^{(11,23)}$.

Subjects with TMD referred cervical region pain more frequently than subjects without this disorder. A positive association between painful symptoms in the cervical region and the presence of TMD was previously described ${ }^{(5-9,10)}$ suggesting that subjects with this disorder have twice the risk of being affected by cervical pain ${ }^{(2)}$
CCD was present in $100 \%$ of subjects of both groups, however, it was symptomatic in $88.24 \%$ of G1 and in $51.35 \%$ of G2. In another study, silent CCD was significantly more frequent in TMD patients, when compared to a control group ${ }^{(10)}$. The authors described the silent CCD as a group of signs of cervical disorder that do not lead to the pain triggering in the region. The results of the present study are opposed to the findings mentioned above, since comparatively to the control group, the CCD symptomatic was more frequent in the TMD group. Such findings can be due to the fact that all subjects were women who present greater vulnerability to painful stimuli ${ }^{(15)}$.

In this study, it became evident that subjects without TMD present higher frequency of light degree and lower of moderate or severe degree of CCD than TMD group, demonstrating a relation between TMD and CCD severity. In the literature, a greater prevalence of CCD has also been observed in patients with TMD, regardless the nature of the disorder ${ }^{(8,10)}$.

A recent study reported a correlation between the cervical and mandibular disability, meaning that people with craniomandibular pain present functional cervical disability besides the functional mandibular disability, ${ }^{(24)}$. In another study, without the purpose of verifying the cause-effect relation between TMD and CCD, the authors concluded that there is a reciprocal relation between signs and symptoms of both disorders ${ }^{(25)}$.

There was no difference between the groups regarding the cervical column mobility. This corroborates the results of other studies, where the presence of TMD did not result in a restriction of cervical spine movements ${ }^{(7,26)}$

In general, most part of the subjects of both groups did not present articular noises during cervical movements. Nevertheless, the difference between groups reached a value close to the significance level ( $\mathrm{p}=0.05)$, since $20.59 \%$ and $5.41 \%$. of G1 and G2 subjects, respectively, presented noises during movements. The quality of cervical movements evaluated by means of CCDI was shown to be related to the presence and severity of TMD ${ }^{(1)}$. 
A higher frequency of pain during two or more cervical movements was observed in TMD group. The cervical mobility evaluation did not confirm such association, since there was no difference between groups, supporting the hypothesis of hyperalgesia in TMD patients ${ }^{(27,28)}$.

The possibility of an association between hyperalgesia and TMD motivated researches investigating the generalized perception of pain in subjects affected by such disorder. For this, some authors proposed to evaluate the pain threshold at pressure in areas distant from the orofacial region. Pain threshold at pressure was lower in hipotenar region ${ }^{(27)}$ and also in other body areas ${ }^{(28)}$ in subjects with TMD compared to asymptomatic subjects. Therefore, the sensibilization at central level may be one of the explanations to the comorbidity between CDD and TMD and also support the algic complaints referred in several parts of the body by subjects with myogenic and mixed TMD ${ }^{(15)}$. The pain provoked test during palpation of the cervical muscles resulted in difference between groups, with more frequent pain symptom in four or more cervical areas in TMD subjects.

Patients with TMD report pain more frequently during palpation to the muscles of the upper body, especially the cervical ones ${ }^{(10)}$. In a recent study, the authors reported association between pain in the masticatory and trapezius and sternocleidomastoideus muscles in subjects with myogenic $\mathrm{TMD}^{(29)}$. Additionally, among the cervical signs and symptoms that accompany the TMD severity, the pain during palpation of cervical muscles was the most important in this association ${ }^{(1)}$.

The previously mentioned generalized hyperalgesia may explain a more frequent perception of pain during cervical movements and a greater sensibility to the palpation of the cervical muscles observed in the study group.

\section{CONCLUSION}

Among the studied subjects there was no difference in the craniocervical posture

of subjects with and without TMD. It suggests that the postural changes are more related to CCD occurrence.

The presence of TMD resulted in a higher frequency of painful symptom in the cervical region and referred pain during tests of range of movement and palpation of the cervical muscles. Therefore, it is believed that the coexistence of signs and symptoms of CDD and TMD may be more related to the common innervation of the trigeminocervical complex and to the hyperalgesia in subjects with TMD than to the craniocervical posturedisorder.

Therefore, aspects related to the cervical spine must be considered by all professionals involved in the assessment and treatment of patients with TMD. Additionally, the TMD evaluation must be more complete, including not only the orofacial region, in order to provide a more comprehensive view of the disorders that affect the craniocervicomandibular complex.

\section{REFERENCES}

1. Bevilaqua-Grossi D, Chaves TC, de Oliveira AS. Cervical spine signs and symptoms: perpetuating rather than predisposing factors for temporomandibular disorders in women. J Appl Oral Sci. 2007;15(4):259-64.

2. Ciancaglini R, Testa M, Radaelli G. Association of neck pain with symptoms of temporomandibular dysfuntion in the general adult population. Scand J Rehabil Med. 1999;31(1):17-22.

3. Wallace C, Klineberg IJ. Management of craniomandibular disorders. Part 1: a craniocervical dysfunction index. J Orofac Pain. 1993;7(1):83-8.

4. Armijo-Olivo S, Magee DJ, Parfitt M, Major P, Thie NM. The association between the cervical spine, the stomatognathic, system and craniofacial pain: a critical review. J Orofac Pain. 2006;20(4):271-87.

5. Pedroni CR, de Oliveira AS, Bérzin F. Pain characteristics of temporomandibular disorder: a pilot study in patients with cervical spine dysfunction. J Appl Oral Sci. 2006;14(5):388-92.

6. Oliveira AS, Bermudez CC, Souza RA, Souza CM, Castro CE, Berzin F. Avaliação multidimensional da dor em portadores de desordem temporomandibular utilizando uma versão brasileira do questionário McGill de dor. Rev Bras Fisioter. 2003;7(2):151-8.

7. De Wijer A, Steenks MH, de Leeuw JR, Bosman F, Helders PJ Symptoms of the cervical spine in temporomandibular and cervical spine disorders. J Oral Rehabil. 1996;23(11):742-50.

8. De Laat A, Meuleman H, Stevens A, Verbeke G. Correlation between cervical spine and temporomandibular disorders. Clin Oral Investig. 1998;2(2):54-7.

9. Visscher CM, Lobbezoo F, de Boer W, van der Zaag J, Naeije M. Prevalence of cervical spinal pain in craniomandibular pain patients. Eur J Oral Sci. 2001;109(2):76-80.

10. Stiesch-Scholz M, Fink M, Tschernitschek H. Comorbidity of internal derangement of the temporomandibular joint and silent dysfunction of the cervical spine. J Oral Rehabil. 2003;30(4):386-91.

11. Lau KT, Cheung KY, Chan KB, Chan MH, Lo KY, Chiu TT. Relationships between sagittal postures of thoracic and cervical spine, presence of neck pain, neck pain severity and disability. Man Ther. 2010;15(5):457-62.

12. Corrêa EC, Bérzin F. Temporomandibular disorder and dysfunctional breathing. Braz J Oral Sci. 2004;3(10):498-502.

13. da Silveira MC, Sígolo C, Quintal M, Sakano E, Tessitore A. Proposta de documentação fotográfica em motricidade oral. Rev CEFAC. 2006;8(4):485-92.

14. Schürks M, Diener HC. Migraine allodynia, and implications for treatment. Eur J Neurol. 2008;15(12):1279-85.

15. Sarlani E, Greenspan JD. Evidence for generalized hyperalgesia in temporomandibular disorders patients. Pain. 2003;102(3):221-6.

16. Browne PA, Clark GT, Kuboki T, Adachi NY. Concurrent cervical and craniofacial pain. A review of empiric and basic science evidence. Oral Surg Oral Med Oral Pathol Oral Radiol Endod.1998;86(6):633-40.

17. Dworkin SF, LeResche L. Research diagnostic criteria for temporomandibular disorders: review, criteria, examinations and specifications, critique. J Craniomandib Disord. 1992;6(4):301-55.

18. Visscher CM, De Boer W, Lobbezoo F, Habets LL, Naeije M. Is there a relationship between head posture and craniomandibular pain? J Oral Rehabil. 2002;29(11):1030-6.

19. Iunes DH, Carvalho LC, Oliveira AS, Bevilaqua-Grossi D. Craniocervical posture analysis in patients with temporomandibular disorder. Rev Bras Fisioter. 2009;13(1):89-95.

20. Matheus RA, Ramos-Perez FM, Menezes AV, Ambrosano GM, HaiterNeto F, Bóscolo FN, et al. The relationship between temporomandibular dysfunction and head and cervical posture. J Appl Oral Sci. 2009;17(3):204-8.

21. Currie P, Lobo-Lob S, Stark P, Mehta N. The effect of maxillary molar distalization on cervical posture. Int J Stomatol Occlusion Med. 2009;2(2):65-9.

22. Tecco S, Tete S, Festa F. Relation between cervical posture on lateral skull radiographs and electromyographic activity of masticatory muscles in caucasian adult women: a cross-sectional study. J Oral Rehabil. 2007;34(9):652-62.

23. Silva AG, Punt TD, Sharples P, Villas-Boas JP, Johnson MI. Head posture and neck pain of chronic nontraumatic origin: a comparison between patients and pain-free persons. Arch Phys Med Rehabil. 2009;90(4):669-74. 
24. Olivo SA, Fuentes J, Major PW, Warren S, Thie NM, Magee DJ. The association between neck disability and jaw disability. J Oral Rehabil. 2010;37(9):670-9.

25. Wiesinger B, Malker H, Englund E, Wänman A. Does a dose-response relation exist between spinal pain and temporomandibular disorder? BMC Musculoskelet Disord. 2009;10:28.

26. Sipilä K, Zitting P, Siira P, Laukkanen P, Järvelin MR, Oikarinen KS, et al. Temporomandibular disorders, occlusion, and neck pain in subjects with facial pain: a case-control study. Cranio. 2002;20(3):158-64.
27. Sherman JJ, LeResche I, Mancl LA, Huggins K, Sage JC, Dworkin SF. Cyclic effects on experimental pain response in women with temporomandibular disorders. J Orofac Pain. 2005;19(2):133-43.

28. Vierck CJ. Mechanisms underlying development of spatially distributed chronic pain (fibromyalgia). Pain. 2006;124(3):242-63.

29. Pallegama RW, Ranasinghe AW, Weerasinghe VS, Sitheeque MA. Influence of masticatory muscle pain on electromyographic activities of cervical muscles in patients with myogenous temporomandibular disorders. J Oral Rehabil. 2004;31(5):423-9. 